\title{
Transit-Oriented Development Suitability Analysis by the Analytic Hierarchy Process and a Geographic Information System: A Prototype Procedure
}

\author{
Reza Banai \\ The University of Memphis
}

\begin{abstract}
A prototype procedure is illustrated to assess the suitability of land use around proposed light rail transit stations of a metropolitan area, with an example of a focus on one station area land use pattern. Transit oriented development (TOD) guidelines provide the criteria for an assessment. The procedure for assessment is facilitated by a geographic information system (GIS), and the Analytic Hierarchy Process (AHP), a multicriteria methodology that is increasingly employed in conjunction with geographic information systems. The weights of the criteria are determined through paired comparisons (relative measurement), and a ratings intensity scale is used to determine the scores of land units (absolute measurement). This flexibility in measurement is helpful in situations where land use criteria, such as TOD guidelines, as suitability factors and with certain desirable thresholds of intensity are known, but must be considered strategically and adaptively, responsive to local priorities and site-specific conditions. The scores of land uses on a scale of zero to 100 percent are determined, which indicate the degrees of the suitability of a transit station area as a potential
\end{abstract}


TOD. As well, the proportions suggest changes that target particular parcels-individually and as a group-so as to bring about a desirable mix of the public, core/ employment, and housing uses for an urban TOD. This prototype application highlights the versatile properties of the AHP, particularly when used in the specific context of a development paradigm (TOD) in conjunction with a geographic information system that has not been previously addressed in the literature on applications.

\section{Introduction}

A view of ecology as a whole system encompasses not only the natural but also the built environment. The physical form that human settlement must take, then, is integral to the debates about sustainability and ecology, the balance of the natural and human-made systems. A recent contribution cognizant of a holistic view of ecology is provided by Calthorpe (1993) in his exemplary book, The Next American Metropolis, subtitled Ecology, Community, and the American Dream. Sustainable communities have a physical form that support public transit. A transit-oriented development (TOD) is defined by an average distance of 2000 feet (10-minute walk) from a transit stop, with retail, commercial, and office uses that are centrally located. TODs accommodate a mix of retail, office, residential, and public uses. The spatial configuration of a TOD thus caters to its residents and employees, whether they travel by transit, car, bicycle, or on foot (Figure 1).

Calthorpe (1993) defines three types of TODs - urban, neighborhood, and "secondary areas." The three types of settlement pattern follow a similar principle which defines spatial configuration in relation to a pedestrian scale and which promotes the diversity or mix of uses-commercial, residential, and public. Arguably, they are "new" types in the sense of a contrast with single-use zoning, with a bias in favor of a single mode of transportation-the automobile-which, in part, contributes to urban and suburban sprawl. In contrast to urban sprawl, evident since around the late 1940s in the U.S. and contentiously characterized as inhumane, resource intensive, formless and increasingly deemed as unsustainable, TODs have a more compact, rather than limitless, form. With 


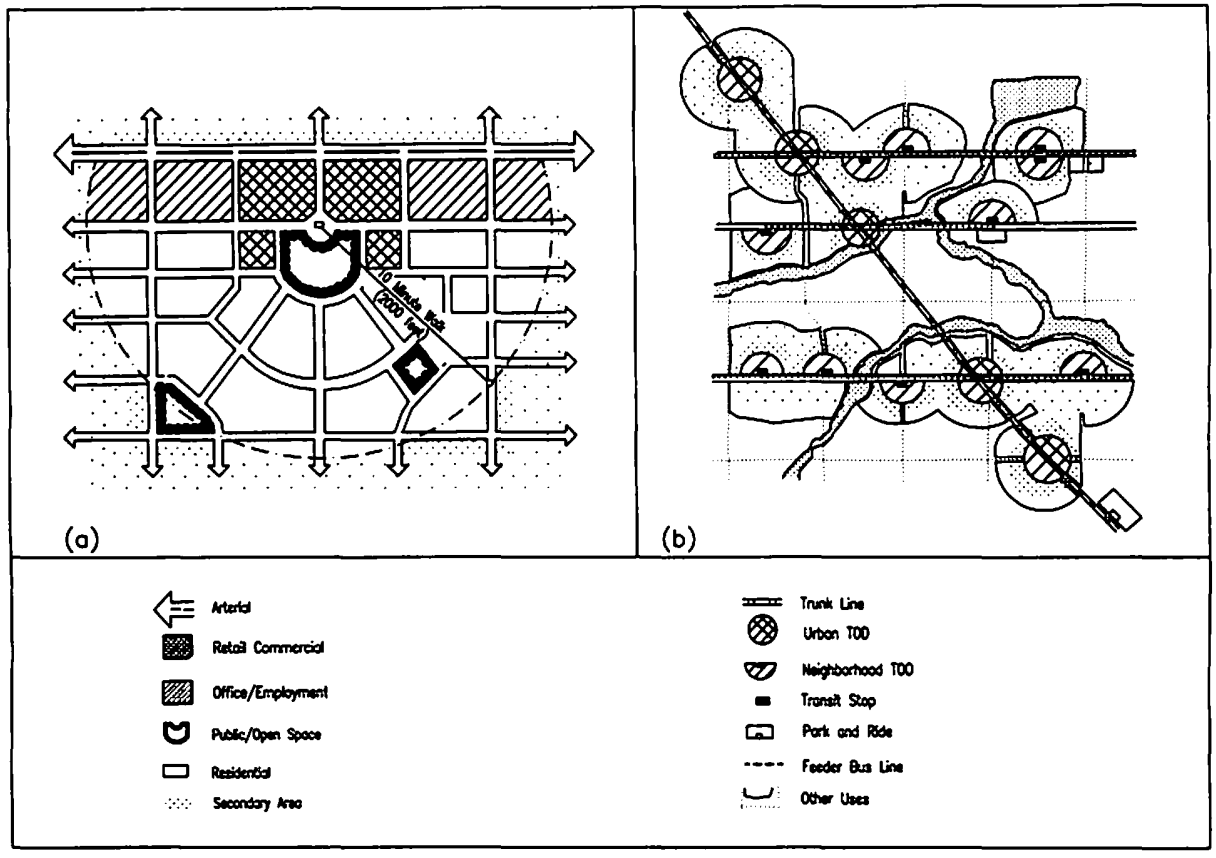

Source: Modified from Calthorpe (1993).

Figure 1. (a) Transit-oriented development (TOD);

(b) Regional location of TODs in relation to circulation.

their mix of uses as well as transportation modes and places in which to live and work, TODs provide alternatives to suburban sprawl.

A set of principles guide the physical form of TODs, whether in new growth areas or in "infill," redevelopment. The principles address a combination of social, spatial, economic, ecological, and organizational goals conducive to the (re)creation of transit-oriented developments. The principles serve as a backdrop for the specification of a set of design guidelines. The design guidelines address both the general and the specific-for example, the proportion of TOD areas devoted to public, employment, and housing uses; the density of housing; the location of civic buildings; parking and circulation; and general configuration of buildings (see Calthorpe 1993 for details).

The guidelines are not seen as a "universal model," however, thereby making adaptation of them in response to the conditions specific to a locality or a 
region plausible (Calthorpe 1993: 52; see also 42). Judicious appraisal, adoption, or modification of the guidelines involve an assessment of the conditions specific to a site that is commensurate with the small, spatial size of a TOD area (2000 feet radius from a transit station). A procedure that aids in the assessment of the relative importance of TOD guidelines as criteria as well as in the ratings of the site parcels relative to the criteria is outlined in the next section. This procedure uses the analytic hierarchy process, which is increasingly applied as a multicriteria methodology of site assessment in conjunction with geographical information systems. The properties of the AHP that make it particularly appropriate in the specific context of a development paradigm (TOD) and a GIS are highlighted.

The AHP is a robust multicriteria methodology in situations involving factor diversity. This AHP property is particularly useful since TOD guidelines specify a combination of qualitative and quantitative factors. Furthermore, the weights of the criteria are determined by means of paired comparisons. This property is of particular relevance in situations where the relative importance of site suitability factors must be determined in context rather than assumed on the basis of general models or previous empirical studies. Even TOD guidelines, as Calthorpe (1993) emphasizes, are better thought of when considered in context rather than universally applied. The AHP aids in the (re)formulation of TOD guidelines in context with a process of weighing the multiple criteria for site assessment. Above all, land use/transportation planning epitomizes planning in the face of the uncertainties of the economic, demographic, and political environment. The expert planning team encounters the uncertainties of the decisions of other participantsthe present and future residents of a community, the developer, the financier, the politician. Furthermore, values and circumstances change, and decisions are made in the face of limited information. In contrast to other multicriteria methods, the AHP provides a measure to gauge the consistency of value judgments of the decisionmakers in the process of deciding the relative importance of the criteria. Thus, the AHP provides an alternative to the commonly-used methods, particularly useful in decisionmaking under conditions of limited information and un- 
certainty, where the inconsistency in judging the relative importance of the criteria in a site suitability analysis can be both detected and improved. ${ }^{\prime}$

The method of paired comparisons of factors with reciprocal matrices (relative measurement) is unique to the AHP. However, the ratings of the alternatives when standards are known is performed in the AHP (absolute measurement) similar to other multicriteria methods. Both relative and absolute scales of the AHP were used with a geographical information system to develop a prototype procedure to assess TOD suitability. Focus was on an area within 2000 feet radius of a proposed light rail transit station. The focused site is located in an area that is designated as an "urban center," characterized by mixed residential, commercial, office, and governmental uses, internally-oriented design and higher densities, and a variety of services in close proximity to the service population (Memphis 2000 Policy Plan 1981). This concept of an urban center suggests an affinity with the concept of an urban TOD. Thus, an impetus is provided for the development of a procedure for an assessment of the focused site as an urban TOD as well as an urban center. This prototype procedure is intended as a contribution to the planners' "tool kit" in situations (such as in planning for a TOD) which, as Calthorpe notes, involve "areas larger than single parcels but smaller than those typically covered in community plans" (Calthorpe 1993:51).

\section{Transit Oriented Development Suitability Analysis: An Application of the Analytic Hierarchy Process with a Geographical Information System}

\section{Problem Context}

A recent study conducted for the local transit authority in the city of Memphis (Tennessee) has identified the locations of light rail (LRT) stations along the already existing railroad lines (Figure $3 \mathrm{c}$ ). Ridership, travel time, station spacing, and proximity to concentrations of shopping and employment activity were among the factors considered in the proposed location of LRT stations. The study itself notes, however, that the final decision on the location of stations is contingent upon station area land use, access plans, and station designs. Each transit station location may thus be considered as a catalyst for station area de- 
velopment or redevelopment (infill), as well as for enhanced transit accessibility.

Given the preliminary location of LRT stations, station area land use suitability was then to be determined. Certain properties or factors that make a place transit-friendly are known in the literature (for example, see Cervero 1993; Bernick and Cervero 1997; Ewing et al. 1997). As also noted above in Calthorpe's transit-oriented development guidelines, certain desirable thresholds are considered if places are to sustain an orientation to transit. For example, accessibility as a factor is considered with a threshold of a maximum of 2000 feet or (10-minute walk) from the surrounding housing to the transit station. At distances beyondfor example, 3,000 feet from the station-more people use a bus rather than walk to the transit station. (For a comparison of the different thresholds and mode shares, see Bernick and Cervero 1997.) Moderate-to-high density is also a suitability factor in TOD. Furthermore, land use mix, in contrast to single-use designation is considered not only as a factor in promoting transit use but also in enhancing the sustainability of TOD itself, as a "balanced" place that contains employment, shopping, and living activities. Since TODs cater to vehicular traffic as well as pedestrian movement, the circulation network is both continuous and hierarchically-differentiated to promote efficiency and safety of circulation.

The determination of the suitability of a station area land use as a potential TOD, it turns out, is a particular case of a more general problem of land use/site evaluation involving multiple factors as criteria. In the section that follows, one method - the AHP - among a class of multicriteria evaluation methods is illustrated as a prototype procedure to assess transit-oriented development suitability analysis within a GIS.

\section{TOD Suitability Analysis by the AHP with GIS}

Since its inception in the 1970s by Saaty (1977), and despite its wide-ranging disciplinary applications (e.g., see Zahedi 1986; Saaty and Vargas 1987), the AHP has relatively recently received attention as a multicriteria land evaluation/ site assessment method, particularly in conjunction with geographical information systems. (e.g., see Banai 1989, 1993; Xiang and Whitley 1993; Malczewski 
1996; Lin et al. 1997). (See Saaty [1992] for detailed exposition of the theory, applications, and extensions of the AHP method. For a brief introduction, particularly in the GIS context, see Banai [1993]). The basic AHP properties are outlined thus:

(a) Hierarchical Structure. The systemic concept of a hierarchy is used to structure a multicriteria evaluation problem. The criteria, the subcriteria (if any), and the alternatives are represented at the various levels of a typical AHP hierarchy of interrelated of factors. The factors at each lower level are compared with respect to the factors at the higher level of the hierarchy. First, the relative importance of the criteria is determined, followed next by the importance of the subcriteria, and finally down to the lowest level in the hierarchy in which the alternatives are rated.

(b) Paired Factor Comparison. At the core of the AHP is a systematic procedure for determining the relative importance of factors through their paired comparisons and by using a ratio scale. The weights of $n$ factors, $A_{1}, A_{2}, \ldots, A_{n}$ are denoted by a vector

$$
\mathrm{w}=\left(\mathrm{w}_{1}, \mathrm{w}_{2}, \ldots, \mathrm{w}_{\mathrm{n}}\right)
$$

Paired comparisons of the factors are performed in a matrix

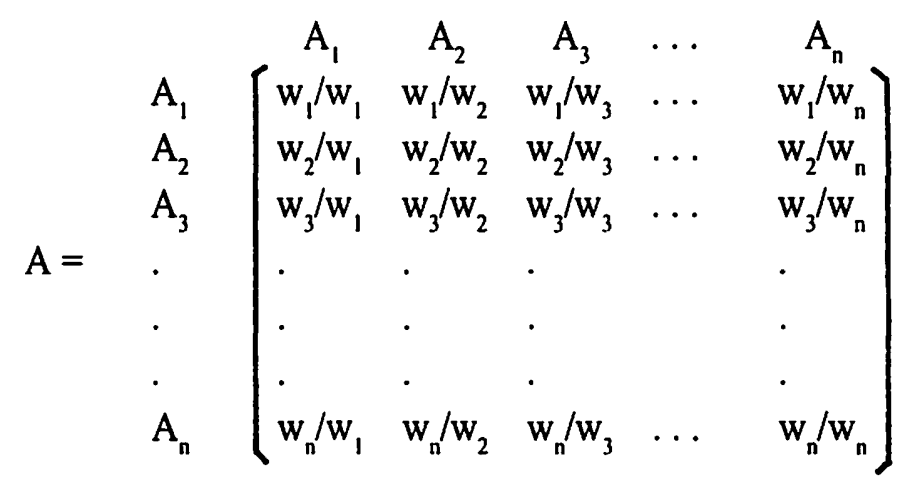


The matrix A is reciprocal $\left(a_{i j}=1 / a_{j j}\right)$, consistent $\left(a_{i j}=a_{i k} / a_{j k}\right)$, and all its diagonal entries are one $\left(a_{i i}=1\right)$. The coefficients (or entries) of $A$ give the relative magnitudes of the $n$ factors $\left(a_{i j}=w_{i} / w_{j}\right)$ when the vector of weights $w=$ $\left(\mathrm{w}_{1}, \mathrm{w}_{2}, \ldots, \mathrm{w}_{\mathrm{n}}\right)$ is known. However, if the weights are not known, they can be recovered by solving the well-known characteristic value problem. That is A is (post) multiplied by $\mathrm{w}$ and the result is stated in proportion to $\mathrm{w}$ itself, with $\mathrm{n}$ as a scalar.

$$
\mathrm{A} \cdot \mathrm{w}=\mathrm{n} \cdot \mathrm{w}
$$

Since A has unit rank (there is only one independent row of A), all of its characteristic values $\lambda_{\mathrm{i}}(\mathrm{i}=1 \ldots, \mathrm{n})$ are zero except one which Saaty $(1980)$ has denoted by $\lambda_{\text {max }} \neq \lambda_{i}=0$. The system $A \cdot \mathrm{w}=\mathrm{n} \cdot \mathrm{w}$ is stated in the form

$$
\mathrm{A} \cdot \mathrm{w}=\lambda_{\max } \cdot \mathrm{w}
$$

The weights of the factors compared pairwise in matrix A are thus determined by the normalized principal characteristic vector of $A$. The vector of weights $\mathrm{w}$ is recovered from any column of $\mathrm{A}$. A unique solution is obtained upon normalization of the columns of $A$ (each $w_{i}$ entry is divided by the column total $\Sigma w_{i}$. for $\mathrm{i}=1, \ldots, \mathrm{n})$.

c. Calculus of Consistency. When the vector of weights $w$ is known, matrix $A$ is consistent. That is, $a_{i j} \cdot a_{j k}=a_{i k}$.

However, when $w$ is unknown and the coefficients of $A$ are estimates of the relative weights, then the condition of consistency may not hold. That is, $a_{i j} \cdot a_{j k}$ $\neq \mathrm{a}_{\mathrm{ik}}$. A small perturbation in the values of the coefficients of $A$ implies a small perturbation in $\lambda_{\max }$. When $A$ is consistent, $\lambda_{\max }=n$. But, in general, $\lambda_{\max } \geq n$ (Saaty, 1980). The closer the value of $\lambda_{\max }$ is to $n$, the more consistent are the estimated coefficients of $A$ and therefore the better the estimated solution vector w. Hence, deviation from consistency is measured by an index:

$$
\mathrm{CI}=\left(\lambda_{\max }-\mathrm{n}\right) /(\mathrm{n}-1) .
$$


This value is compared with its average value for a randomly-generated reciprocal matrix of the same size as A. The comparison indicates whether the ratio estimates in the pariwise comparison matrix $\mathrm{A}$ are closer to being logically consistent or are closer to being random (Saaty 1980). Saaty has suggested an upper limit of 10 percent as a measure of good consistency. When this 0.10 threshhold is exceeded, the ratio estimates are revised to improve consistency. Thus, a procedure is provided that offers a gauge on consistency of judgment when violated in multicriteria evaluation in the face of limited information, data imperfection, factor diversity, and uncertainty.

(c) Synthesis. Once the relative weights of the factors at the various levels of the hierarchy-from the criteria to the alternatives-are determined, the results are aggregated in a weighted summation procedure in which the scores of the alternatives are computed.

The AHP was used interactively with a geographic information system (GIS) (a) to determine the relative importance of TOD suitability factors as criteria, (b) to analyze ratings of groups of land parcels with thematic maps of spatial data, and, finally, (c) to display the composite criteria-weighted ratings score of TOD land use suitability.

In the site study, ArcCAD (ESRI, Inc., Redlands, $C A$ ) was used for analysis of GIS data and thematic maps, AutoCAD (Autodesk, Inc., San Rafael, CA) was used as the drawing editor for the maps, and Expert Choice (1988, Decision Support Software, Inc., McLean, VA)was used for multicriteria assessment, utilizing the Analytic Hierarchy Process. The GIS information included parcel boundaries, census tract information (1996 Tiger/line files), road and street centerlines, zoning, and building outlines (local public utility company). The parcel data (shape files) were the most utilized in the assessment of land use suitability. This GIS data source provided the (city and county) tax assessors' use occupancy codes, which were useful for identifying and grouping land uses. The parcels were grouped (by use occupancy codes) as suggested by the TOD guidelines, as public, core/employment, and housing. After ratings were derived from Expert Choice, the resulting weights were then re-entered with the GIS data for map evaluation. Figure 2 illustrates the GIS data and software utilization. 


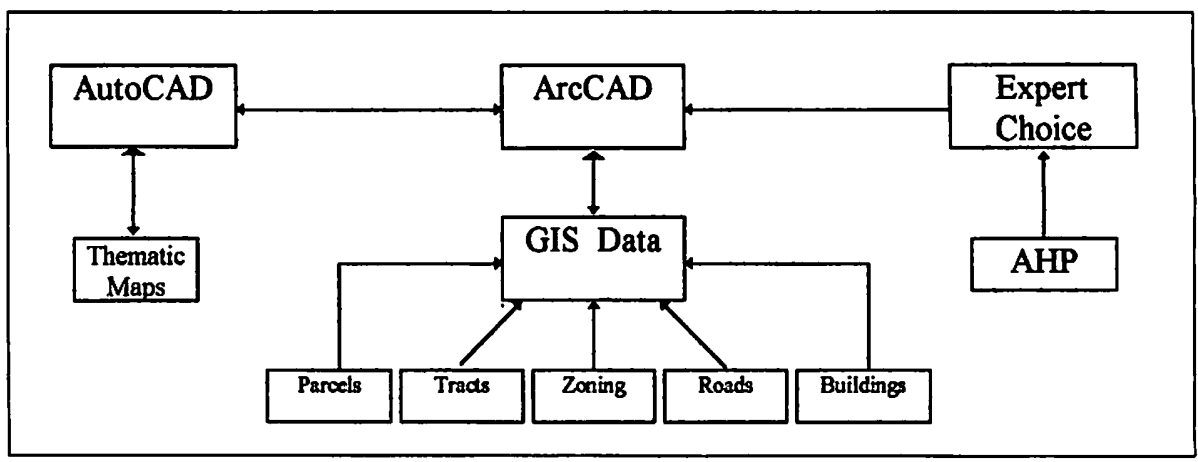

Figure 2. GIS data and software application for TOD suitability analysis.

Within the ArcCAD environment, GIS information is organized by multiple themes. In this example, parcel information was grouped by like use occupancy codes into themes such as public, core/employment, and housing. This information was then queried, clipped, buffered, and analyzed to determine total areas, and proximities.

As noted above, because situations and circumstances vary, TOD criteria should be considered judiciously, responsive to the conditions specific to a locality. If the TOD criteria (suitability factors) are not to be considered as fixed, universally held standards, then the relative importance of the criteria must be devised responsive to the local circumstances and in accordance with locally determined "standards." The AHP's logic of pairwise comparison (relative measurement) aids in the derivation of the relative weights of the suitability factors.

Once the relative importance of the context-dependent criteria is determined, the next step involves the ratings of the land uses to assess suitability for TOD. The AHP's logic of absolute measurement aids in this process of determining the relative merit of land uses given the TOD criteria. With the combined steps, the versatile properties of the AHP are used in a situation that involves multicriteria evaluation with both relative and absolute scales of measurement. This flexibility of the AHP, particularly in situations where land use guidelines, such as TOD (criteria), as suitability factors and with certain desirable, albeit modifiable, thresh- 
olds are known, is not highlighted in the literature on the application of the AHP as a site suitability technique with a geographical information system.

\section{Deriving the Relative Weights of TOD Suitability Factors}

A hierarchy is constructed in which four suitability factors and their subfactors are specified (Figure 3a). The alternatives as urban and neighborhood TODs, and secondary areas, comprising three land use groupings (public, core/ employment, and housing) are specified at the final branchings of this hierarchy.

The choice of the four suitability factors is strategic. It represents a realistic scenario in which a group of decisionmakers, having considered a general set of suitability factors, focus upon those that are deemed critical to a particular site. Not only, then, do the decisionmakers "narrow-down" the suitability factors to those which are particularly critical to the conditions of a given site, but they also see fit to discern their relative importance, rather than to assume that factors are equally important at any location. In effect, the decisionmakers set out to derive local "standards" from the general TOD criteria. An example of a procedure that aids in this type of suitability analysis and decisionmaking follows.

The four suitability factors are compared pairwise in a matrix (Table 1) by using the AHP scale (see p. 57).

Regarding the entries in the first row, the reciprocal value $(1 / 3)$ indicates that Density (column factor) is moderately more important than MixUse (row factor). Also in the first row, MixUse is given a value (2) in the mid-point of the scale of equal and moderate importance, in comparison with RoadNet. MixUse and ProxStat are considered as equally important (1).

Considered alone, density — particularly moderate to high density—is a factor deemed essential to a transit-supportive development. Considered together with the mix of uses, however, density is given a "moderately" greater importance (3). Why is density given only a "moderately" greater importance than the mix of uses, if moderate-to-high density is essential to a transit-supportive development? Because the "balance," e.g., with respect to jobs-housing, that an appropriate mix of land uses in a development provides is desirable in itself, whether or not transit is available. In the spirit of the guidelines, a TOD is not only a 


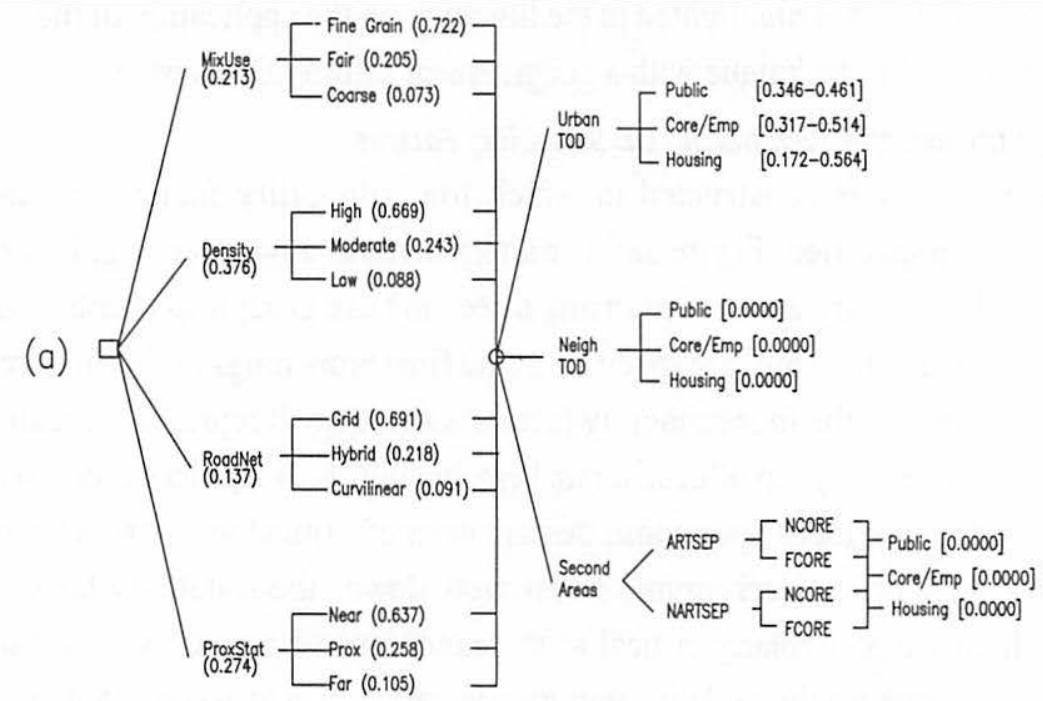

(b)
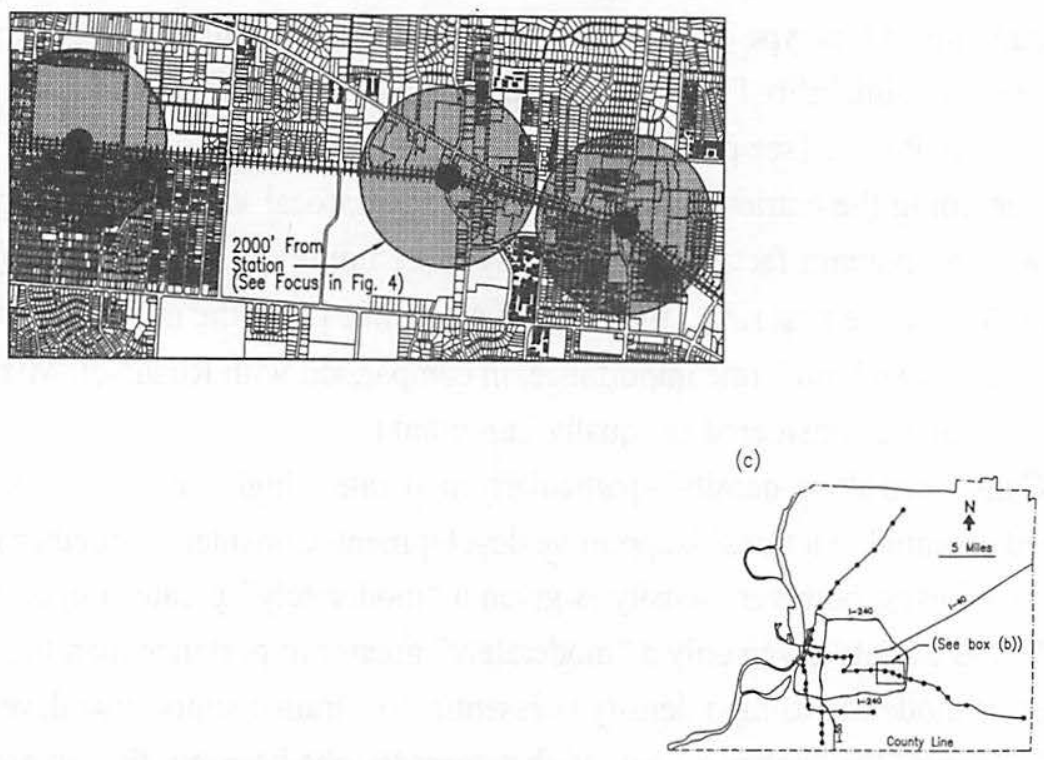

Figure 3. (a) A hierarchy for TOD land suitability analysis of a station area; (b) proposed transit stations; (c) regional LRT lines and stations. 


\section{The AHP Scale: Definition and Explanation}

Equal importance-the two activities contribute equally to the objective

Moderate importance-experience and judgment slightly favor one activity over another

Essential or strong importance-experience and judgment strongly favor one activity over another

Demonstrated importance-an activity is strongly

favored and its dominance is demonstrated in practice

Extreme importance-the evidence favoring one activity over another is of the highest possible order of affirmation

Intermediate values between the two adjacent judgments-compromise is needed.

If an activity $i$ has one of the above numbers assigned to it when compared with activity $j$, then $j$ has the reciprocal value when compared with $i$. above numbers

*The scale 1.1. 1.2, ... 1.9, or an even finer one, can be used to compare elements that are close together or are near equal in importance; similarly from 2.0 to 2.9, etc. (Source: Saaty1987)

transit-supportive development but is also a balanced or finer-grained development. Hence, also, the usefulness of a multicriteria logic of the AHP with paired comparisons of the TOD suitability factors is suggested. The comparisons of the remaining factors follow a similar logic of multicriteria evaluation.

It should be noted that once the upper (or lower) diagonal entries are assigned values in the matrix in Table 1, the lower (or upper) entries are determined reciprocally, without the use of further judgment. Also note that all the diagonal entries are unity, when a factor is compared to itself. The relative weights of the factors (bounded on a scale from zero to 100 percent) are determined by 
Table 1

Deriving Relative Weights of the TOD Suitability Factors

\begin{tabular}{lccccc}
$\begin{array}{l}\text { Suitability } \\
\text { Factor }^{*}\end{array}$ & MixUse & Density & RoadNet & ProxStat & Weight \\
\hline MixUse & 1 & $1 / 3$ & 2 & 1 & 0.213 \\
Density & 3 & 1 & 2 & 1 & 0.376 \\
RoadNet & $1 / 2$ & $1 / 2$ & 1 & $1 / 2$ & 0.137 \\
ProxStat & 1 & 1 & 2 & 1 & 0.274 \\
Consistency & & & & & \\
Index (C.I.) $=0.057$ & & & & & \\
\hline
\end{tabular}

(a) MixUse: The mix of public, corelemployment, and housing uses in the site, distinguished further by the subfactor, fine grain, fair, and coarse (see Fig. 3a). Density: The density of land uses in the site, distinguished by high, moderate and low densities of uses. RoadNet: The road pattern in the transit station area, distinguished by a grid or a curvilinear network of streets, or by a combination, hybrid. ProxStat: The proximity of the public. core/employment, and housing to the transit station, further differentiated by near, proximate, and far (Fig. 3a).

the normalized principal characteristic vector of this matrix. The relative weights of the suitability factors are shown in the right margin of the matrix in Table 1. In a descending order of relative importance, the factors are Density (0.376), ProxStat (0.274), MixUse (0.213), and RoadNet (0.137). Note also that the consistency index value of 5.7 percent is well within the 10 percent range of an acceptable limit, which indicates good consistency in the matrix of ratio estimates of the relative weights of the suitability factors.

At the second branchings of the hierarchy (Figure 3a) the relative importance of subfactors is determined. The subfactors indicate a gradation of the main factors. Through paired comparisons, the "grade" of "membership" of the subfactors is determined. The use of the terminology of fuzzy set logic is deliberate. For example with respect to MixUse, even a "coarse" land use mix is considered for suitability, albeit with a much lower priority $(0.073)$, in compari- 
son to a "fair" (0.205), and to the highly desirable "fine grain" $(0.722)$ land use pattern. The paired comparisons of the subfactors and their relative weights (or grades of membership) are given in Table 2. These comparisons provide examples of how preferences are revealed as the suitability factors are differentiated.

Next, the ratings of the land uses in the site are determined. The ratings are then weighted by the relative importance of the suitability factors (above), and thus the final scores for the various units of land use are determined.

Table 2

Paired Comparisons of the Subfactors

\begin{tabular}{lccccccccc}
\hline MixUse & Fine & Fair & Coarse & Wt. & Density & High & Mod. & Low & Wt. \\
Fine & 1 & 5 & 7 & 0.722 & High & 1 & 3 & 7 & 0.669 \\
Fair & $1 / 5$ & 1 & 4 & 0.205 & Moderate & $1 / 3$ & 1 & 3 & 0.243 \\
Coarse & $1 / 7$ & $1 / 4$ & 1 & 0.073 & Low & $1 / 7$ & $1 / 3$ & 1 & 0.088 \\
C.I. $=0.107$ & & & & & C.I. $=0.006$ & & & &
\end{tabular}

RoadNet Grid Hybrid Curv. Wt. ProxStat Near Prox. Far Wt.

$\begin{array}{lccccccccc}\text { Grid } & 1 & 4 & 6 & 0.691 & \text { Near } & 1 & 3 & 5 & 0.637 \\ \text { Hybrid } & 1 / 4 & 1 & 3 & 0.218 & \text { Prox. } & 1 / 3 & 1 & 3 & 0.258 \\ \text { Curvilinear } & 1 / 6 & 1 / 3 & 1 & 0.091 & \text { Far } & 1 / 5 & 1 / 3 & 1 & 0.105 \\ \text { C.I. }=0.046 & & & & & \text { C.I. }=0.033 & & & & \end{array}$

\section{Rationale for Site Ratings}

Mix Use-The mix of land uses, as derived by the AHP, is ranked second among our four criteria with a weight of 0.213. As Calthorpe (1993: 63) states, "TODs must be mixed-use and contain a minimum amount of public, core commercial and residential uses." The mix of uses provides preferred thresholds to consider when evaluating TOD land uses. The preferred range of ideal mix of uses for an urban TOD is shown in Table 3, compared to the actual mix of uses determined for our site.

The amount of public land use is approximately three times that of the preferred, while the core/employment is in the middle of the preferred range. The 
percentage of residential land use is only 8 percent, which falls short of the preferred range of 20-60 percent. This suggests that some of the public land uses could be readjusted or converted to housing to bring the overall land uses within the suggested range.

The subfactors of this criterion were defined as "fine grain" with a weight of 0.722 , "fair" with a weight of 0.205 , and "coarse" with a weight of 0.073 . These subfactors indicate how each occupancy code group contributes to a desirable overall mix of uses. A "fine" rating indicates that the proportion of land use types is comparable to those found in the TOD guidelines. The goal of this is to maintain balance between the different land use groups to achieve a sustainable mix of uses.

\begin{tabular}{|lclc|}
\hline \multicolumn{4}{|c|}{ Table 3} \\
Preferred vs. Observed Mix of Uses \\
\hline Preferred Mix of Use & Urban TOD & Actual Mix of Use & Site \\
\hline Public & $5-15 \%$ & Public & $47 \%$ \\
Core/Employment & $30-70 \%$ & Core/Employment & $45 \%$ \\
Housing & $20-60 \%$ & Housing & $8 \%$ \\
\hline
\end{tabular}

Two public uses-parks and churches-dominate the site area (Figure 4). These uses comprise 47 percent of the total land area. Large-scale regional parks are more desirable in a TOD's secondary area rather than in its primary area, which accommodates a number of small scale parks as open spaces (recall Figure 1). The regional park extends beyond the 2,000 ft. radius and into the "secondary area." Park/open space land was given a rating of "fair" due to a disproportionate use of land within a TOD area. Within the core/employment area, department stores, strip shopping, restaurants, fast food places, and service stations dominate and justify a "coarse" rating. The presence of two supermarkets, and a few banks are more proportional to the amount of land use mix; therefore, 
a rating of "fair" was given. The amount of land area occupied by the mix of offices, and their distribution helped them attain a rating of "fine." As for the housing component of land use mixes, which totaled only 8 percent of the given area, the single family and duplex uses were assigned a rating of "coarse." The lack of sufficient proportions of these two uses was seen as detrimental to the area. The planned-unit-developments and condominiums ranked higher since they occupied more area in proportion to that of the other groups. However, again as with other two groups making up the category, the amount of land use is below the mix of uses as suggested by the TOD guidelines and was assigned "fair" rating.

Density-Density, with a weight of 0.376 , was determined to be the most important of the four criteria. The number of dwelling units per acre (du/ac) is an indicator of density. The ideal urban TOD as described by Calthorpe has an average residential density of $18 \mathrm{du} / \mathrm{ac}$. The gradation of the subfactors includes ratings above and below this average threshold of density. The subfactor choices of density are "high," with a weight of 0.669 , "moderate," with a weight of 0.243 , and "low," with a weight of 0.088 . Each land use unit (occupancy code group) is thus rated for contribution to the overall density of the area as an urban TOD. Due to the large area and few public buildings, park/vacant land was rated as "low." In contrast, the religious/institutional land uses were given a "high" rating due to the size of the buildings relative to the area of land they occupy (floor area ratio).

The core/employment land uses such as banks, strip shopping, supermarkets, restaurants, fast food places, and service stations were assigned a rating of "low" due to the predominance of parking lots and characteristically low density one-story buildings. Department stores and office land uses were given a rating of "moderate" due to the larger multistory mall and Sears department store. The presence of several multistory office buildings in this area helps to increase the overall density, supportive of transit-oriented development, and therefore these were assigned "moderate" rating. The housing land uses of duplex and single family were both assigned "low" ratings. Calthorpe assigns single family homes 


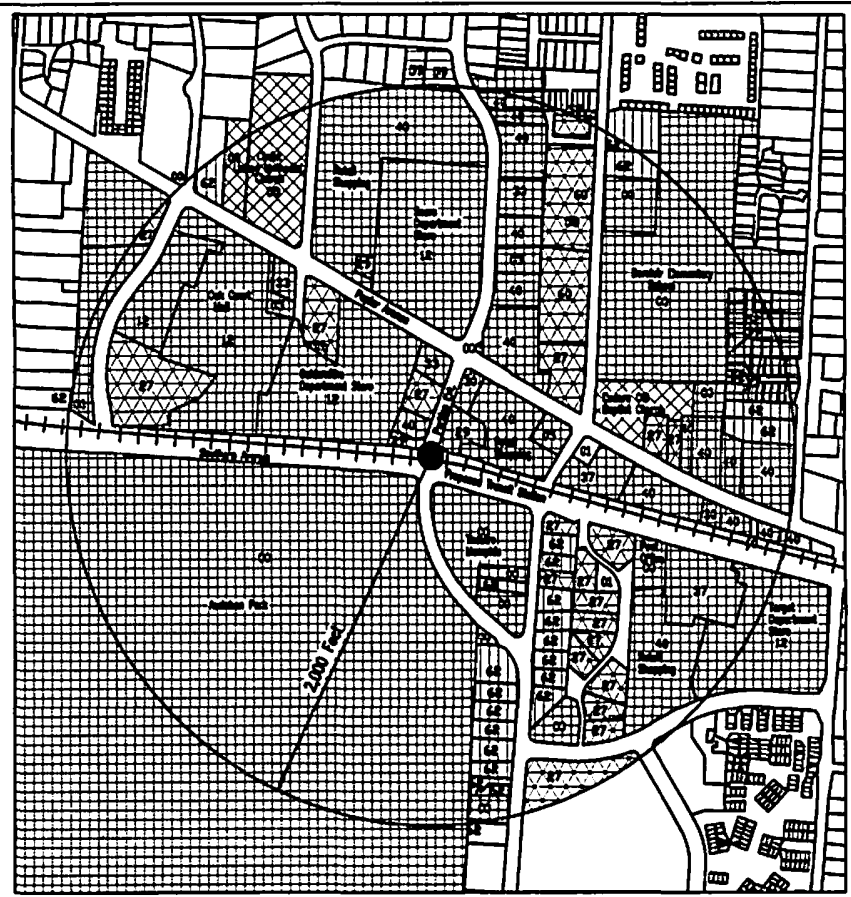

\begin{tabular}{|c|c|c|c|c|c|c|}
\hline & & & Mixuse & Density & RoodNet & ProxStot \\
\hline P & F Perk/Nocont Lond $(00)$ & [osut] & Foir & Low & Grid & Near \\
\hline & Religious(08) & [avis] & Fair & High & Grid & Prox \\
\hline •/Employment & 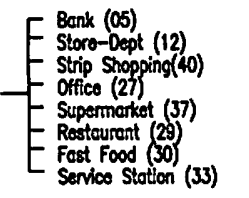 & 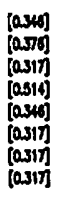 & $\begin{array}{l}\text { Foir } \\
\text { Coorse } \\
\text { Coorse } \\
\text { Fine } \\
\text { foir } \\
\text { Coorse } \\
\text { Coorse } \\
\text { Cocrse }\end{array}$ & $\begin{array}{l}\text { Low } \\
\text { Noderate } \\
\text { Low } \\
\text { Moderete } \\
\text { Low } \\
\text { Low } \\
\text { Low } \\
\text { Low }\end{array}$ & $\begin{array}{l}\text { Grid } \\
\text { Grid } \\
\text { Grid } \\
\text { Grid } \\
\text { Grid } \\
\text { Grid } \\
\text { Grid } \\
\text { Grid }\end{array}$ & $\begin{array}{l}\text { Near } \\
\text { Neor } \\
\text { Neor } \\
\text { Neor } \\
\text { Neor } \\
\text { Neor } \\
\text { Near } \\
\text { Necr }\end{array}$ \\
\hline Hous & 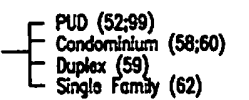 & 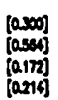 & $\begin{array}{l}\text { Fair } \\
\text { Foir } \\
\text { Cocrse } \\
\text { Cocrse }\end{array}$ & $\begin{array}{l}\text { Moderote } \\
\text { High } \\
\text { Low } \\
\text { Low }\end{array}$ & $\begin{array}{l}\text { Grid } \\
\text { Grid } \\
\text { Grid } \\
\text { Grid }\end{array}$ & $\begin{array}{l}\text { Prox } \\
\text { Near } \\
\text { For } \\
\text { Prox }\end{array}$ \\
\hline
\end{tabular}

Land Use Suitability Rotings:

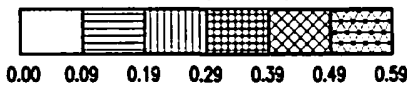

Source: Occupancy codes (in paremthese's) from public domain GIS (1996).

Figure 4. Land use suitability ratings for an urban TOD. 
a density of 7-10 du/ac, and duplexes 10-14 du/ac. This is, again, due to their low density, which is preferred in secondary-area developments. The planned unit developments (mainly townhouses) were assigned a "moderate" rating due to their higher residential densities, which average 18-29 du/ac. The condominiums in the area, particularly the 12-story one on Perkins, with a density of 40-65 du/ac, received "high" rating.

RoadNet-The road network criterion, which is assigned an overall weight of 0.137 (the lowest of the four) is based on the traffic circulation system found within each use occupancy code group of parcels for that land use. The three choices of ratings are "grid" $(0.691)$, "hybrid" $(0.218)$, and "curvilinear" $(0.091)$. A "grid" rating means that the overall street pattern exhibits parallel lines of travel, with a regular, continuous network of arterial and collector streets, preferably with an axial orientation to the transit station. The "hybrid" rating is a combination of some grid pattern and curvilinear streets. The "curvilinear" rating is reserved for street patterns, which do not allow a continuous or through traffic flow, similar to those found in suburban residential neighborhoods with many coves and dead-end streets.

The street pattern for each occupancy code and the overall transit station area itself is a grid. The main arterial streets (Poplar Avenue and Perkins/Perkins Extended) (Figure 4) both pass through or near the proposed transit stop and serve as collector streets from outlying residential areas. Therefore, each use occupancy code was assigned a rating of "grid" with a weight of $(0.095)$.

ProxStat-The proximity to transit station criterion, which is assigned a weight of 0.274 (the second highest of the four), is simply based on the overall distance of each group of parcels with the same use occupancy code from the proposed transit stop. The choices of ratings for this criteria are "near" $(0.637)$, "proximate" (0.258) and "far" (0.105).

The majority of use occupancy code groups, such as park/vacant land, bank, department store, strip shopping, office, supermarket, fast food place, service station, and condominium were assigned a rating of "near" because of the close proximity and equality of distributions around the proposed transit stop. The 
groups of religious, PUDs, and single-family were assigned a rating of "proximate." The two large church parcels are located on the north side of the proposed transit stop, approximately 1,000 feet to $1,800 \mathrm{ft}$. away, respectively. The planned unit developments are located within the $2,000 \mathrm{ft}$. radius, which, by TOD definition, justify a "proximate" rating. The duplexes are located just outside the north side of the 2,000 foot radius boundary, resulting in a "far" rating.

\section{Conclusion}

The AHP-GIS procedure illustrated here facilitates small area suitability assessment beyond individual parcels and at a scale of "district" rather than metropolitan-wide comprehensive planning. The detailed, micro investigation of the smaller area or district plan, however, provides input into the larger comprehensive plan of which it is a part. By identifying and grouping land parcels into units of the public, core/employment, and housing land uses, the composition of the area as a whole is determined for suitability as a transit-oriented development. The holistic perspective is particularly important to a concept of a "balanced" TOD, if followed through methodologically. The AHP aids in such an investigation of the appropriate proportion and composition of a TOD.

By using four criteria as an illustration, the suitability of the various units of land use, which constitute the still larger units of public, core/employment, and housing, is determined. It turns out that certain land uses fare favorably when the area as a whole is viewed as a TOD (see Figure 4). For example, among the uses with highest scores include religious uses $(0.481)$, office $(0.514)$, and condominium (0.584) within public, core/employment, and housing groups, respectively. The ranges of the final scores by the three categories (see also Figure 2a, urban TOD branching) indicate only housing $(0.172-0.567)$, with a low score in the range, lagging behind those of the public $(0.346-0.461)$ and core/employment $(0.317-0.514)$. As noted above, conversion or redevelopment of land (for example, vacant) into residential uses could result in a more favorable score of housing in a transit-oriented development.

One can allow for even greater complexity by increasing the number of levels or factors in a decisionmaking hierarchy. The participants (e.g., experts, 
developers, publics, politicians) are identified explicitly. Thereby, the different priorities that different participants attach to the TOD suitability factors as criteria are accounted for. A possible scenario in which the weightings of the criteria result in an outcome that favors one party more than another may be examined. The AHP predictions of such an outcome could inform the parties involved and thus provide a basis so as to arrive at a collectively desirable decision outcome. ${ }^{2}$

This prototype analysis provides only a stepping stone for further investigation. For example, the use of census GIS data is helpful to determine areas of growth or decline. These areas can be analyzed to determine suitability for new, in-fill, or redevelopment TODs. New trunk line and station locations might be considered, based on the interpretation of rapid population growth and zoning changes in suburban areas, particularly in relation to new regional malls and activity centers, which have burgeoned recently. Joint consideration of transit spacing and station area (TOD) criteria could justify alternative transit station locations other than those currently proposed along the existing truck lines (based on transit functional requirement and regional distribution of activity centers). GIS themes can be developed quickly to show transit, bus routes, stops, or proposed road design changes as thematic maps. The socioeconomic (e.g., income, auto ownership), demographic (e.g., population characteristics, density), and physiographic profiles of the region can be mapped thematically with available GIS census data to facilitate both the depiction and analysis of land use/transportation. nexus. The AHP aids in such a GIS analysis to fine-tune public policy priorities for future transit-oriented developments in the region.

\section{Endnotes}

' The AHP is widely applied and therefore has also received both critical and constructive consideration of its properties. The issues regard the scale, treatment of objectivity, procedures for aggregation of weights, and methods of ranking alternatives. For a survey of applications and areas of methodological extensions, see e.g., Zahedi (1986) and Forman (1993) for a lucid discussion of "facts and fictions" about the AHP. 
${ }^{2}$ For a historical account of a transport planning process from the perspectives of different participants or "actors," see Hall (1980), especially Chapter 3, "London's Motorways."

\section{References}

Banai, R. 1993. Fuzziness in geographical information systems: Contributions from the analytic hierarchy process. International Journal of Geographical Information Systems (7)4: 315-329.

Banai, K. R. 1989. A new method for site suitability analysis: The analytic hierarchy process. Environmental Management 13: 685-693.

Bernick, M., and R. Cervero R. 1997. Transit villages in the 21st century. New York: McGraw-Hill.

Calthorpe, P. 1993. The next American metropolis: Ecology, community and the American dream. New York: Princeton Architectural Press.

Cervero R. 1993. Transit-supportive development in the United States: Experiences and prospects. Washington, D.C.: Federal Transit Administration.

Ewing, R., B. Mackey, and B. Sewell. 1997. Transit-oriented development in Florida. Land Development (10)2: 31-35.

Forman, E. H. 1993. Facts and fictions about the analytic hierarchy process. Mathematical and Computer Modelling (17)4/5: 19-26.

Hall, P. 1980. Great planning disasters. California: Univ. of California Press.

Lin H., Q. Wan, X. Li, J. Chen, and Y. Kong. 1997. GIS-based multicriteria evaluation for investment environment. Environment and Planning B: Planning and Design 24: $403-414$.

Malczewski, J. 1996. A GIS-based approach to multiple criteria group decision-making. International Journal of Geographical Information Systems (10)8: 955-971.

Saaty, T. L. 1992. Multicriteria decision making-the analytic hierarchy process. Pittsburgh, PA: RWS Publications.

Saaty, R.W. 1987 The analytic hierarchy process-what it is and how it is used. Mathematical Modelling (9)3-5: 161-176.

Saaty, R.W., and L. G. Vargas (eds.) 1987. The analytic hierarchy process: Theoretical developments and some applications. Mathematical Modelling (9)3-5.

Saaty, T. L. 1980. The analytic hierarchy process. New York: McGraw-Hill. 
Saaty, T. L. 1977. A scaling method for priorities in hierarchical structures. Journal of Mathematical Psychology 15: 234-281.

Xiang, W. N., and D. L. Whitley. 1994. Weighting land suitability factors by the PLUS method. Environment and Planning B: Planning and Design 21: 273-304.

Zahedi, F. 1986. The analytic hierarchy process: A survey of the method and its applications. Interfaces (16)4: 96-108.

\section{Acknowledgment}

The author would like to thank John Lancaster for research assistance. The comments of the reviewers on an earlier version of this paper are gratefully acknowledged.

\section{About the Author}

Reza Banal, Ph.D., is a Professor of City and Regional Planning at the University of Memphis in Tennessee. 